\title{
PELESTARIAN BAHAN PUSTAKA \\ DI PERPUSTAKAAN UNIVERSITAS NEGERI SRIWIJAYA
}

Nabila Ainun Nazifah, Yessy Suwanti, Tata Lestari, Aan Ardiyanto*

Abstract: The purpose of this research is to know more deeply about: (a) the technique of preservation of library materials used at the Library of Sriwijaya University, (b) to know the process of library material preservation at library of Sriwijaya University, (c) to know the cause of material damage, (d) to know the obstacles faced in the implementation of library material preservation at the Library of Sriwijaya University. The methods used in this research are descriptive approach, observation and interview. The conclusion of this research is the technique used in library material conservation is using binding technique with perfect binding method and book covering. The process of library material preservation starts from the selection of damaged books by the selving officer of 30 copies. Then just done preservation or improvement within 2-3 days.

Keyword : Library material preservation, University library

\section{Pendahuluan}

Ketika seseorang memasuki ruangan perpustakaan guna untuk mencari literatur yang ada diperpustakaan hal pertama yang diperhatikannya adalah kondisi perpustakaan dan kondisi bahan pustaka. Keadaan koleksi bahan pustaka menurut Afrizal Sirano dalam kegiatan hari buku nasional, beliau mengatakan bahwa bukan hanya fasilitas ruangan yang mempengaruhi minat baca pemustaka, namun kondisi bahan pustaka juga mempengaruhi, karena apabila kondisi bahan pustaka yang masih bagus dan informasi didalamnya masih sangat aktual maka hal ini akan menarik minat pemustaka

*Mahasiswa S1 Program Studi Ilmu Perpustakaan Fakultas Adab dan Humaniora, UIN Raden Fatah Palembang. 
untuk datang ke perpustakaan dan membaca buku lebih giat. ${ }^{1}$ Meningkatnya minat baca di perpustakaan mempengaruhi kualitas sebuah lembaga perpustakaan. Untuk itu demi menjaga koleksi agar tetap baik perlu dilakukannya proses pelestarian bahan pustaka. Pelestarian bahan pustaka merupakan sebuah proses yang harus dilakukan oleh Lembaga Perpustakaan. Sebagaimana dikatakan oleh Hazen dikutip oleh Gardjito, mengenai istilah pelestarian bahan pustaka meliputi 3 ragam kegiatan, yaitu: ${ }^{2}$

1. Kegiatan-kegiatan yang ditunjukkan untuk mengkontrol lingkungan perpustakaan agar dapat memenuhi syarat-syarat pelestarian bahan pustaka yang tersimpan didalamnya.

2. Berbagai kegiatan yang berkaitan dengan usaha-usaha untuk memperpanjang umur bahan pustaka, misalnya dengan cara deasidifikas, laminasi, atau penjilidan ulang.

3. Seluruh kegiatan yang berkaitan dengan usaha untuk mengalihkan isi informasi dari satu bentuk format atau matrik kebentuk lain. Setiap kegiatan menurut kategori-kategori tersebut itu tentu saja masih dapat dikembangkan lagi kedalam berbagai aktifitas lain yang khusus dan rinci.

Pelestarian bahan pustaka menurut IFLA (International Federation of Library Assocoation) memiliki istilah sebagai berikut: ${ }^{3}$

1. Preservation, yaitu memiliki artian luas yang mencangkup unsur-unsur pengelolaan, keuangan, cara penyimpanan, tenaga, tehnik, dan metode untuk melestarikan informasi dan bentuk fisik bahan pustaka.

2. Konservation, yaitu tehnik yang digunakan untuk melindungi bahan pustaka dari kerusakan dan kehancuran dengan cara pengawetan .

Sedangkan, The American Heritage Dictionary mendefinisikan preservasi sebagai usaha untuk melindungi dari segala macam

${ }^{1}$ Indah purwani, "penjilidan buku perpustakaan (library binding) : sejarah dan seni menjilid koleksi bernilai tinggi", jurnal Visipustaka Vol. 17 No. 2, ( agustus 2016), 130

2 Andi Ibrahim, "Perawatan dan pelestarian bahan pustaka", Jurnal Khizanah alHikmah Vol. 1, No. 1 (januari-juni 2002), 4

${ }^{3}$ Ganang Nanda Budiwirawan, “Analisis pelestarian koleksi bahan pustaka tercetak pasca bencana banjir diperpustakaan ceria, desa jleper, kecamatan mijen, kabupaten demak", Jurnal IImu Perpustakaan Vol.4, No.3(juli 2015), 3 
kerusakan, resiko, dan bahaya kerusakan lainnya, agar tetap utuh dan menyiapkan sesuatu untuk melindungi dari kehancuran. ${ }^{4}$ Sedangkan pengertian pelestarian bahan pustaka yang dikemukakan oleh IFLA dan ditetapkan sebagai pedoman pelestarian oleh Perpustakaan Nasional Indonesia, mencangkup 3 aspek, yaitu: ${ }^{5}$

1. Semua aspek usaha untuk melestarikan bahan-bahan, caracara untuk pengolaan, keuangan, sumber daya pelaksananya, metode, dan tehnik-tehnik penyimpanan bahan-bahan pustaka.

2. Semua kebijakan dan kegiatan yang bersangkutan dengan pengawetan / konservesi yaitu cara-cara khusus untuk melindungi bahan-bahan pustaka tersebut

3. Semua langkah untuk mempertimbangkan dan melaksanakan pemugaran atau restorasi, yaitu cara-cara yang digunakan untuk memperbaiki bahan-bahan pustaka yang rusak .

Pelestarian bahan pustaka dapat dilakukan di lembaga perpustakaan Universitas, salah satunya yaitu Universitas Negeri Sriwijaya (Unsri). Universitas yang terletak di Sumatera Selatan. Di Unsri memeliki fasilitas perpustakaan yang sudah menjadi contoh untuk perpustakaan Universitas lainnya, namun masih banyak sekali terlihat koleksi yang ada diperpustakaan kondisinya sudah tidak baik lagi. Padahal banyak mahasiswa/i yang berkunjung dan membutuhkan informasi dari koleksi yang ada diperpustakaan mengingat koleksinya sudah mencapai 4.622 judul atau 5691 eksemplar buku dan perpustakaan Unsri sudah menerapkan kegiatan pelestarian bahan pustaka. Seharusnya perpustakaan melakukan perawatan atau pelestarian yang lebih intensif lagi agar koleksi yang ada diperpustakaan dapat digunakan dengan semaksimal mungkin, dan agar informasi yang seharusnya didapat oleh pemustaka tidak terhambat karena kondisi fisik dari bahan pustaka yang tidak baik atau rusak. Oleh sebab itu penulis tertarik untuk mengkaji lebih dalam lagi mengenai efektif dan intensif atau tidaknya proses pelestarian bahan pustaka di Unsri.

\footnotetext{
${ }^{4}$ Fatkhurrokhman, "Preservasi bahan pustaka di perpustakaan museum: Studi kebijakan preservasi diperpustakaan museum sonobudoyo", Jurnal Fihris Vol. III, No. 1 (Januari 2008), 7

${ }^{5}$ Amhar, "Program pelestarian bahan pustaka di perpustakaan IAIN Imam Bonjol Padang", Jurnal Imam Bonjol, Vol. 1, No.2 ( 02 september 2017),150
} 


\section{Rumusan Masalah}

1. Bagaimana teknik pelestarian bahan pustaka yang diterapkan di perpustakaan Unsri?

2. Bagaimanakah proses pelestarian bahan pustaka di perpustakaan Unsri?

3. Apa saja penyebab kerusakan bahan pustaka di perpustakaan Unsri?

4. Apasaja kendala yang dihadapi dalam melakukan proses kegiatan pelestarian bahan pustaka di Unsri sehingga masih banyak koleksi yang terlihat rusak?

\section{Tujuan Penelitian}

1. Untuk mengetahui teknik apa saja yang digunakan dalam melakukan pelestarian bahan pustaka di perpustakaan unsri.

2. Untuk mengetahui bagaimanakah proses pelestarian bahan pustaka di perpustakaan Unsri.

3. Untuk mengetahui apa saja yang menjadi penyebab kerusakan bahan pustaka di perpustakaan Unsri.

4. Untuk mengetahui kendala apa saja yang dihadapi pada saat proses pelestarian bahan pustaka.

\section{Metode Penelitian}

Metode yang digunakan didalam penulisan ini adalah metode pendekatan deskriptif. Data yang dikumpulkan didapat melalui observasi langsung ke perpustakaan Unsri dan melakukan wawancara langsung dengan Bapak Toha, yang merupakan satu-satunya pekerja dibagian pelestarian bahan pustaka di perpustakaan Unsri. Wawancara dilakukan berjuan untuk mendapatkan informasi yang benar-benar fakta, tidak hanya melalui pendapat-pendapat orang lain.

\section{Pembahasan}

Menurut Undang - Undang Republik Indonesia No. 43 Tahun 2007 Tentang Perpustakaan Pasal 1 ayat (1) menyebutkan, Perpustakaan adalah institusi pengelola koleksi karya tulis, karya cetak, dan/atau karya rekam secara profesional dengan sistem yang baku guna memenuhi kebutuhan pendidikan, penelitian, pelestarian, 
informasi, dan rekreasi bagi pemustaka. ${ }^{6}$ Salah satu jenis perpustakaan adalah perpustakaan Universitas, perpustakaan universitas merupakan lembaga pendidikan yang menyediakan sumber informasi untuk belajar sesuai dengan kebutuhan civitas akademika dan masyarakat pengguna, serta melayani tanpa membedakan suku, bangsa, agama, jenis kelamin, latar belakang dan pendidikan serta perbedaan lainnya seperti mahasiswa masingmasing program studi, dosen atau tenaga administrasi. ${ }^{7}$ Menurut kami, perpustakaan universitas merupakan salah satu fasilitas yang harus dilengkapi oleh universitas guna untuk menunjang Tri dharma perguruan tinggi. Poin dari Tri dharma perguruan tinggi ini adalah: pendidikan dan pengajaran, penelitian dan pengembangan, serta pengabdian kepada masyarakat.

Salah satu fungsi utama di lembaga perpustakaan adalah memberdayakan koleksi agar mampu menunjang layanan perpustakaan secara maksimal. Memberdayakan koleksi agar tetap dalam keadaan baik perlu dilakukannya proses pelestarian bahan pustaka. Pelestarian bahan pustaka dilakukan guna untuk mencegah kerusakan dini pada bahan pustaka dan melindungi bahan pustaka dari faktor alam maupun manusia untuk itu perlu dilakukannya proses pelestarian bahan pustaka. Pelestarian bahan pustaka harus mendapatkan dukungan dan kerjasama dari berbagai pihak pengelola perpustakaan khususnya di bidang pelestarian bahan pustaka, termasuklah dukungan anggaran. ${ }^{8}$ seperti halnya di perpustakaan Unsri mereka sudah menerapkan kegiatan pelestarian bahan pustaka dengan salah satu teknik yang ada dalam melaksanakan kegiatan pelestarian bahan pustaka.

\section{Teknik pelestarian bahan pustaka di perpustakaan Unsri}

Teknik pelestarian bahan pustaka sangat banyak sekali macamnya dan dengan tujuan yang berbeda-beda namun dengan manfaat yang sama. Maksudnya adalah teknik pelestarian bahan pustaka ini menghasilkan cara yang dapat melindungi atau mencegah

\footnotetext{
${ }^{6}$ Perpustakaan Nasional RI, "Standar Nasional Perpustakaan Khusus Instansi Pemerintah", (Jakarta: Perpustakaan Nasional RI, 2014), 3

${ }^{7}$ Ibid., 4

${ }^{8}$ Hamdana, "Pelestarian bahan pustaka di perpustakaan Universitas Indonesia Timur"(Makasar: UIN Alauddin, 2016), 2
} 
kerusakan dini pada bahan pustaka. Teknik-teknik tersebut dapat berupa sebagai berikut: ${ }^{9}$

- Laminasi

Merupakan proses melindungi permukaan bahan pustaka menggunakan plastik khusus. Laminasi memiliki 2 metode yaitu metode panas dan dingin. Metode panas dapat dilakukan dengan metode manual yaitu menggunakan strika, dan metode dingin dapat dilakukan dengan menggunakan double tip sebagai alat perekat plastik khusus tersebut.

- Mending ( menambal)

Merupakan kegiatan menambal permukaan dokumen yang bolong dengan menggunakan tisu khusus yang bebas asam . jenis tisu yang digunakan biasanya merupakan tisu tradisional buatan tangan orang jepang.

- Deasidifikasi

Merupakan kegiatan atau proses untuk menetralisir kandungan atau kadar keasaman didalam kertas . setelah melalui proses deasidifikasi maka kandungan $\mathrm{Ph}$ kertas menjadi seimbang.

- Bleacing

Merupakan kegiatan yang dilakukan bertujuan untuk memutihkan bahan pustaka yang sudah menguning, akibat terkena noda atau yang lainnya.

- Penjilidan

Merupakan kegiatan melindungi bahan pustaka dari kerusakan bisa menggunakan hard cover, dan juga penjilidan dapat dilakukan dengan menggunakan benang, paku dan steples .

Point-point diatas merupakan jenis pelestarian bahan pustaka yang dapat digunakan di lembaga perpustakaan. Berdasarkan data yang kami peroleh melalui wawancara langsung dengan bapak Toha, beliau mengatakan bahwa perpustakaan Unsri melakukan pelestarian bahan pustaka dengan menggunakan teknik penjilidan. Penjilidan buku perpustakaan dikenal dengan istilah library binding. Teknik ini dipandang sebagai teknik yang paling mudah untuk dilakukan

\footnotetext{
${ }^{9}$ Yeni Budi Rachman, "Preservasi dan Konservasi bahan pustaka”, (Depok: Rajawali Pers, 2017), 74
} 
dilembaga perpustakaan. Menurut bapak Toha penjilidan bahan pustaka tidak perlu pendidikan khusus hanya saja diperlukan ketekunan untuk melakukannya dengan baik dan benar. Beliau mengatakan seperti itu sebab beliau bukanlah seorang pustakawan yang berlatar belakang pendidikan ilmu perpustakaan. Beliau hanyalah tamatan SLTA, Kegiatan pekerjaan menjilid bisa diajarkan dengan demonstrasi dan dikomentari pada setiap operasionalnya. Akan tetapi, setiap penanganan praktik demonstrator kadang sangatlah membingungkan bagi pemula untuk mengimplementasikan apa yang dimaksud. Hal inilah yang mengakibatkan mengapa metode mengajar secara manual dibutuhkan dengan harapan para pemula akan mampu mengerjakan secara mandiri sesuai dengan tingkat kemampuan yang dimiliki. Penjilidan secara manual yang dilakukan di perpustakaan bertujuan agar perbaikan buku dapat dilakukan secara dini oleh penjilid ataupun petugas perpustakaan. Karakteristik seorang penjilid buku perpustakaan (book binder) adalah "Those bookbinders employed by small shops likely will do a variety of binding duties, while those employed by bigger companies will specialize in one or two tasks, like operating sophisticated manual or electronic guillotine paper cutters or folding machines. Other workers may concentrate their efforts in the preparation and adjustment of machines, as well as repairing devices as required". ${ }^{10}$ Jadi berdasarkan teori diatas menunjukkan bahwa apabila seseorang ingin menekuni bidang penjilidan di perpustakaan, harus benar-benar mau terjun secara totalitas agar hasil pekerjaannya benar-benar maksimal.

Penjilidan yang dilakukan sejak awal itu sangatlah sederhana. Hanya menggunakan kertas kambing dan plastik khusus sebagai pelapis bahan pustaka. Kemudia dipunggung buku disatukan menggunakan isolasi hitam yang tebal. Namun sekarang sesuai dengan perkembangan zaman, beliau melakukan penjilidan menggunakan hard cover sebagai pelapisnya, dan steples, benang atau lem sebagai perekatnya. Penjilidan ini memiliki beberapa metode yaitu: ${ }^{11}$

${ }^{10}$ Cockrell Douglas, "Book binding and the care of books", dilihat dalam http:www.about book binding.com, diunduh tanggal 24 mei 2018.

${ }^{11}$ Endang fatmawati, "Analisis kebutuhan pelestarian bahan pustaka tercetak", Jurnal Pustabiblia Vol. 1, No.1, (2017), 13 
- Menjilid dengan benang (thread binding)

Beberapa jenis model jahitan yang masih eksis, dari model dasar yang sederhana sampai yang kompleks dengan banyak ragam jahitan. Sementara itu, umumnya buku dari negara barat banyak jahitan melubangi sepanjang lipatan kertas. Beberapa penjilidan di asia seperti Retchoso atau sistim jilid bentuk kupu terbang dari Jepang yang menggunakan sedikit celah sebagai pengganti lubang.

- Penjilidan dengan lem dikenal dengan perfect binding Merupakan bagian model penjilidan, Perfect binding menggunakan cairan lem untuk menyatukan halaman yang dijahit kemudian digabungkan bersama sampul lunak (soft cover) yang menutupi blok buku. Cover bisa dicetak untuk hasil akhir dari sistem jilid ini .Sementara penjilidan dengan lem (perfect binding) yang menggunakan sampul keras (hard cover) adalah halaman yang ditata dan direkatkan bersama menggunakan lem menjadi bentuk blok buku yang kemudian ditambahkan cover atau penutup sampul yang terbuat dari bord dan kertas, kain, vinyl, atau kulit. Yang termasuk di dalam kelompok penjilidan dengan lem juga adalah penjilidan yang menggunakan lem panas (hot glue) dan biasa disebut dengan thermal binding. Proses pengerjaannya adalah dengan memberikan cairan lem panas sepanjang punggung buku dan merata pada seluruh halaman. Sitem thermo binding hanya bisa mengelem dengan kapasitas maximum $30 \mathrm{~mm}$. (3cm).

Dari berbagai macam metode penjilidan yang ada, kami mendapatkan bahwa di perpustakaan Unsri menggunakan penjilidan dengan metode perfect binding dengan lem yang digunakan adalah lem lilin yang dihangatkan dan menggunakan katron padi sebagai hardcovernya. Metode perfect binding ini mulai dilakukan sekitar kurang lebih tahun 2000 an. Setelah melakukan pelestarian dengan metode perfect binding maka dilanjutkan dengan proses penyampulan plastik hal ini bertujuan agar koleksi yang sudah di jilid dapat terjaga dan terlindungi lebih efektif lagi sehingga tidak menyebabkan kerusakan lebih cepat pada bahan pustaka yang sudah diperbaiki. 


\section{Proses pelestarian bahan pustaka di perpustakaan Unsri}

Dalam melakukan pelestarian bahan pustaka dibutuhkan teknik dan pengetahuan tertentu serta terdapat beberapa prosedur yang harus dilakukan, diantaranya adalah: analisa bahan pustaka, pengumpulan bahan pustaka, dan pelestarian bahan pustaka. ${ }^{12}$ Namun, prosedur yang dilakukan dalam perlestarian bahan pustaka tergantung kebijakan dari perpustakaan masing-masing.

Perpustakaan Unsri merupakan perpustakaan Universitas yang ada di Sumatera Selatan. Perpustakaan ini memberikan pelayanan kepada pegawai, mahasiswa dan bahkan ada dosen juga yang berkunjung ke perpustakaan ini. Oleh karena itu perpustakaan Unsri ini perlu melakukan perawatan, pemeliharaan dan perlindungan terhadap bahan pustaka yang ada.

Berdasarkan hasil observasi dan wawancara yang dilakukan di perpustakaan Unsri kami mendapatkan informasi bahwa proses koleksi sampai ke tahap pelestarian adalah melalui pustakawan di bagian selving. Pustakawan yang berada dibagian selving apabila mendapatkan koleksi-koleksi yang rusak maka langsung memberikannya kepada seseorang yang bekerja di bagian pelestarian bahan pustaka. Berikut adalah prosedur pelestarian bahan pustaka dengan metode penjilidan yang dilakukan di perpustakaan Unsri:

- Pustakawan bagian selving memberikan koleksi yang rusak kepada petugas dibagian pelestarian bahan pustka.

- Petugas di pelestarian bahan pustaka menerima dan mengumpulkan koleksi yang rusak didalam 1 tempat.

- Setelah koleksi terkumpul, petugas mulai melakukan pelestarian per 30 eksemplar buku yang rusak.

- Petugas membuat call number yang baru per 30 eksemplar untuk koleksi yang nantinya sudah di perbaiki.

- Petugas melepas cover dari buku yang akan diperbaiki.

- Petugas merapikan koleksi yang sudah lepas-lepas dan membersihkan lem yang sebelumnya ada di bahan pustaka / melepas steples yang sebelumnya menempel pada bahan pustaka.

${ }^{12}$ Gardjito, "Pedoman teknis penjilidan bahan pustaka", ( Jakarta: Perpustakaan Nasional RI, 2017), 33 
o Petugas memanaskan alat yang digunakan untuk menghangatkan lem lilin.

- Petugas mensteples ulang koleksi dan menempelkan lem hangat kebagian punggung koleksi.

- Petugas menempelkan softcover dan hardcover di permukaan dan belakang koleksi.

- Petugas menggunting koleksi menjadi rata sesuai dengan hardcover yang ditempelkan sebelumnya.

- Kemudian petugas menempelkan sampul pelapis pertama untuk menutupi hardcover dan dilanjutkan dengan menempelkan fotocopy cover sesuai dengan cover koleksinya.

- Petugas menyampul koleksi menggunakan sampul plastik, agar koleksi lebih terlindungi.

- Petugas mencatat judul-judul koleksi yang sudah di perbaiki.

Itulah prosedur / tahapan-tahapan yang dilakukan di perpustakaan Unsri dalam melestarikan bahan pustaka.

\section{Penyebab kerusakan bahan pustaka di perpustakaan Unsri}

Bahan pustaka haruslah dijaga sebaik mungkin karena banyak sekali faktor yang dapat menyebabkan keruskan pada bahan pustaka. Faktor tersebut dapat datang melalui faktor alam, mikroorganism, lingkungan dan manusia. ${ }^{13}$ Faktor lingkungan dapat disebabkan karena keadaan ruangan yang tidak sesuai dengan keadaan bahan pustaka. Untuk itu perpustakaan haruslah memperhatikan akan fasilitas yang ada di perpustakaan tersebut agar semua dapat terkoordinasi atau terpantau dengan baik.

Berdasarkan observasi di perpustakaan Unsri terlihat bahwa perpustakaan Unsri memiliki banyak sekali koleksi tercetak, koleksi tersebut terdiri dari 4.622 judul atau 5.691 eksemplar buku, serta memiliki fasilitas dengan 1 rungan khusus bagian komputer, 1 rungan sampoerna corner, 1 ruangan cafe Neng's bakery, 1 ruangan referensi, dan 2 ruangan koleksi buku tercetak (1 rungan buku tahun 2000 an, dan 1 ruangan buku tahun 1990 an). ${ }^{14}$ Koleksi yang ada

\footnotetext{
${ }^{13}$ Djuandana pamungkas, "Pelestarian bshan pustaka di perpustakaan Stain Kediri”, Jurnal Al-kuttab Vol. 3, No. 1(Januari-juni 2016),13

${ }^{14}$ Perpustakaan Program Pascasarjana Universitas Sriwijaya, di akses di www.pustakappsunsri.com, di lihat pada 24 mai 2018.
} 
diruangan buku tahun 1990 an terlihat banyak yang rusak. Dan kondisi ruangan sepi dan cukup berdebu, oleh karena itu sangat sedikit sekali pemustaka datang berkunjung keruangan tersebut. Berdasarkan observasi, kami menyimpulkan bahwa penyebab kerusakan bahan pustaka di perpustakaan Unsri adalah :

- Suhu dan kelembaban ruangan yang relatif tidak seimbang.

- Cahaya matahari yang langsung mengenai koleksi, karena cahaya ultra ungu dari sinar matahari dapat mengubah warna sampul, mempengaruhi ketahanan kertas, dan cetakan karena proses foto analisis, Sinar fluorescent juga tidak baik bagi bahan pustaka.

- Debu dan polusi yang banyak terdapat di sekitar ruangan.

- Koleksi yang dimakan rayap, koleksi yang berjamur, dll.

- Abrasi (keusan) yang terjadi pada bahan pustaka yang disebabkan perlakuan yang kurang tepat terhadap bahan pustaka dalam pengiriman, penempatan pada rak, frekuensi pemakaian, pemakaian oleh pembaca.

\section{Kendala yang dihadapi pada saat kegiatan pelestarian bahan pustaka}

Kendala yang didapatkan didalam proses kegiatan perpustakaan dapat disebabkan oleh berbagai macam faktor, yaitu kurangnya penerapan management dengan baik, kurangnya anggaran, dan kurangnya tenaga ahli. Penerapan management di perpustakaan sangat penting sekali seperti yang dikatakan oleh Akussah, "Mangement perlu dilakukan dalam proses preservation, dengan management apa yang dituju akan tercapai dengan baik dan berjalan dengan lancar". ${ }^{15} \mathrm{Hal}$ ini tentu selaras dengan perkataan Margaret M. Byrnes, bahwa " management dapat membantu mengurangi apa yang menjadi kendala dalam proses kegiatan yang ada diperpustakaan. Seperti halnya dalam masalah budget apabila sudah dimanagement dengan baik maka tentunya akan meminimalisir pemakaian budget yang berlebihan". ${ }^{16}$ Secara teori

${ }^{15}$ Daniel Olusegun Ikegune, "Management and preservation of non-book materials in academic libraries: a case study of three university libraries in nigeria", e-journal library philosophy and practice (2016), 5

${ }^{16}$ Margaret M. Byrnes, "Preservation and collection management: some common concerns", Collection Building, Vol. 9 Iss: 3, 39-45 
itulah tadi yang merupakan salah satu penyebab dari kendala yang timbul dalam proses perlestarian bahan pustaka. Berdasarkan hasil observasi yang dilakukan di perpustakaan unsri, terlihat bahwa terdapat beberapa kendala yang dihadapi dalam melakukan kegiatan pelestarian bahan pustaka dengan penjilidan metode perfect binding.

1. Kurangnya implementasi management didalam perpustakaan unsri

2. kurangnya SDM atau tenaga ahli dibidang pelestarian bahan pustaka khususnya penjilidan dalam proses pelestarian bahan pustaka. Karena di perpustakan Unsri ini hanya memiliki 1 petugas yang bekerja dibagian pelestarian bahan pustaka maka hal ini menyebabkan banyak koleksi yang rusak belum bisa diperbaiki dengan cepat. Sehingga akan banyak koleksi yang di rak terlihat rusak.

3. Kurang banyaknya atau kurang lengkap alat-alat yang dibutuhkan dalam melakukan kegiatan penjilidan sehingga menghambat proses pelestarian bahan pustaka dengan cepat.

\section{Kesimpulan}

Kesimpulan dari hasil observasi di Perpustakaan Universitas Sriwijaya serta menjawab pertanyaan pada bagian rumusan masalah terlihat bahwa:

1. Teknik yang digunakan dalam pelestarian bahan pustaka di perpustakaan Unsri menggunakan teknik penjilidan dengan metode perfect binding dan dilanjutkan dengan penyampulan.

2. Proses pelestarian bahan pustaka dimulai dari dipilih oleh petugas selving, dikumpulkan per 30 eksemplar kemudian baru dilakukan pelestarian dalam waktu 2-3 hari dan dilakukan penjilidan serta dilakukan pencatatan koleksi yang diperbaiki.

3. Koleksi di perpustakaan unsri terlihat banyak yang kondisinya kurang baik disebabkan oleh ruangan yang keadaan suhunya tidak seimbang, dan banyak koleksikoleksi yang sudah lama. Sehingga memicu untuk datangnya microorganisme yang dapat menyebabkan kerusakan pada bahan pustaka. 
4. Kendala yang dihadapi saat melakukan pelestarian bahan pustaka adalah kurangnya fasilitas yang banyak, dan kurangnya tenaga ahli. SDM yang ada sebagai petugas pelestarian bahan pustaka dapat dikatakan kurang karena tidak sebanding dengan jumlah koleksi yang harus diperbaiki.

\section{Daftar Pustaka}

Amhar, "Program pelestarian bahan pustaka di perpustakaan IAIN Imam Bonjol Padang", Jurnal Imam Bonjol, Vol. 1, No.2 ( 2017),150

Budiwirawan, Ganang Nanda, "Analisis pelestarian koleksi bahan pustaka tercetak pasca bencana banjir diperpustakaan ceria, desa jleper, kecamatan mijen, kabupaten demak", Jurnal IImu Perpustakaan Vol.4, No.3(2015), 3

Byrnes, Margaret M.,"Preservation and collection management: some common concerns", Collection Building, Vol. 9 Iss: 3, 3945

Douglas, Cockrell, "Book binding and the care of books", dilihat dalam http:www.about book binding.com, diunduh tanggal 24 mei 2018.

Fatkhurrokhman, "Preservasi bahan pustaka di perpustakaan museum: Studi kebijakan preservasi diperpustakaan museum sonobudoyo", Jurnal Fihris Vol. III, No. 1 (2008), 7

Fatmawati, Endang, "Analisis kebutuhan pelestarian bahan pustaka tercetak", Jurnal Pustabiblia Vol. 1, No.1, (2017), 13

Gardjito, "Pedoman teknis penjilidan bahan pustaka", Jakarta: Perpustakaan Nasional RI, 2017

Hamdana, "Pelestarian bahan pustaka di perpustakaan Universitas Indonesia Timur"Makasar: UIN Alauddin, 2016

Ibrahim, Andi, "Perawatan dan pelestarian bahan pustaka", Jurnal Khizanah al-Hikmah Vol. 1, No. 1 (2002), 4

Ikegune, Daniel Olusegun, "Management and preservation of nonbook materials in academic libraries: a case study of three university libraries in nigeria", e-journal library philosophy and practice (2016), 5 
Pamungkas, Djuandana, “Pelestarian bshan pustaka di perpustakaan Stain Kediri", Jurnal Al-kuttab Vol. 3, No. 1(2016),13

Perpustakaan Nasional RI, "Standar Nasional Perpustakaan Khusus Instansi Pemerintah", Jakarta: Perpustakaan Nasional RI, 2014 Perpustakaan Program Pascasarjana Universitas Sriwijaya, di akses di www.pustakappsunsri.com, di lihat pada 24 mai 2018.

Purwani, Indah, "penjilidan buku perpustakaan (library binding) : sejarah dan seni menjilid koleksi bernilai tinggi", jurnal Visipustaka Vol. 17 No. 2, (2016), 130

Rachman, Yeni Budi, "Preservasi dan Konservasi bahan pustaka", Depok: Rajawali Pers, 2017 